\title{
Correction to: Differential disruption of conditioned ejaculatory preference in the male rat based on different sensory modalities by micro-infusions of naloxone to the medial preoptic area or ventral tegmental area
}

Gonzalo R. Quintana ${ }^{1} \cdot$ Morgan Birrel $^{1} \cdot$ Sarah Marceau ${ }^{1} \cdot$ Narges Kalantari $^{1} \cdot$ James Bowden $^{1} \cdot$ Yvonne Bachoura $^{1}$. Eric Borduas ${ }^{1} \cdot$ Valerie Lemay $^{1}$ - Jason W. Payne ${ }^{1} \cdot$ Conall Mac Cionnaith ${ }^{1} \cdot$ James G. Pfaus $^{1,2}$

(C) Springer-Verlag GmbH Germany, part of Springer Nature 2020

Correction to: Psychopharmacology

https://doi.org/10.1007/s00213-019-05334-9

After publication of this paper, the authors determined an error in one of the author names: in PubMed Cionnaith CM should be Mac Cionnaith $\mathrm{C}$.

The online version of the original article can be found at https://doi.org/ 10.1007/s00213-019-05334-9

James G. Pfaus

jpfaus@uv.mx

1 Centre for Studies in Behavioral Neurobiology, Department of Psychology, Concordia University, Montréal, QC H4B 1R6, Canada

2 Centro de Investigaciones Cerebrales, Universidad Veracruzana, CP 91193 Xalapa, VER, Mexico 